\title{
The effects of the instantaneous scanning glucose monitoring system on hypoglycemia, weight gain, and health behaviors in patients with gestational diabetes: a randomised trial
}

\author{
Xiaohua Zhang ${ }^{1}$, Dongmei Jiang ${ }^{1}$, Xu Wang ${ }^{2}$ \\ ${ }^{1}$ Department of Obstetrics, Haian People's Hospital, Nantong, China; ${ }^{2}$ Department of Nursing, Affiliated Haian Hospital of Nantong University, \\ Nantong, China \\ Contributions: (I) Conception and design: X Zhang, X Wang; (II) Administrative support: X Wang; (III) Provision of study materials or patients: X \\ Zhang, D Jiang; (IV) Collection and assembly of data: X Zhang; (V) Data analysis and interpretation: X Zhang, D Jiang; (VI) Manuscript writing: All \\ authors; (VII) Final approval of manuscript: All authors. \\ Correspondence to: Xu Wang. Department of Nursing, Affiliated Haian Hospital of Nantong University, ZhongBa middle Road 17 st, Haian, Nantong \\ 226600, China. Email: wangxu_0603@126.com.
}

\begin{abstract}
Background: Gestational diabetes (GDM) can cause adverse effects on parturient and newborns, and effective control of blood sugar levels in the parturient is essential for good prognosis. Continuous dynamic blood glucose monitoring can effectively improve the final pregnancy outcome of patients with GDM.

Methods: A total of 110 GDM patients admitted to our hospital from April 2019 to April 2020 were selected and divided into 2 groups according to the random number table method, with 55 participants in each group. In the control group, fingertip blood glucose monitoring was used, and in the ISGMS group the ISGMS was used in combination with fingertip blood glucose monitoring. The incidence of hypoglycemia, the qualified rate of weight gain at the end of pregnancy, compliance with blood glucose monitoring, and health behavior patterns were compared between the 2 groups.
\end{abstract}

Results: Patients who used the ISGSM showed a lower incidence of hypoglycemia $(\mathrm{P}<0.05)$, a greater qualified rate of weight gain at the end of pregnancy $(\mathrm{P}<0.05)$, had higher blood glucose monitoring compliance $(\mathrm{P}<0.05)$, and demonstrated better health behaviors $(\mathrm{P}<0.05)$ compared to the control group after 2 weeks of intervention.

Conclusion: The application of the ISGMS in patients with GDM improved the compliance of blood glucose monitoring, improved health behaviors, reasonably controlled weight gain, and avoided hypoglycemia.

Trial Registration: Chinese Clinical Trial Registry ChiCTR2100045927.

Keywords: Instantaneous scanning glucose monitoring system (ISGMS); gestational diabetes (GDM); body weight; hypoglycemia; compliance; health behavior

Submitted Jan 21, 2021. Accepted for publication Apr 23, 2021.

doi: $10.21037 /$ apm-21-439

View this article at: http://dx.doi.org/10.21037/apm-21-439

\section{Introduction}

The cause of Gestational diabetes (GDM) is not clear. It can cause severe complications such as polyhydramnios, ketoacidosis, pregnancy-induced hypertension, spontaneous abortion and secondary infections in pregnant women. It can also cause fetal malformations and low fetuses. Blood sugar, stillbirth, hyperbilirubinemia and hypocalcemia, etc. The prognosis of GDM is mainly related to the condition of the patient's diabetes and the control of blood sugar levels, and thus effective blood glucose monitoring is essential (1). Related surveys have shown that continuous dynamic blood glucose monitoring can effectively improve 
the final pregnancy outcome of patients with GDM (2). The pre-pregnancy body mass index (BMI) and weight gain of patients with GDM also have a great impact on the pregnancy outcome, and hence it is necessary to effectively control the BMI and body weight to improve outcomes $(3,4)$. The instantaneous scanning glucose monitoring system (ISGMS) is a new scanning glucose monitoring system based on sensors. Every time when the scanning detector is close to the sensor, the data will be transmitted to the scanning detector. The scanning detector will then display the current glucose level detected by the sensor, along with the glucose trend arrow and the glucose readings in the last eight hours. You can scan at any time to obtain the current glucose data according to your needs; it can also be automatically obtained and stored by the sensor (every 15 minutes). ISGMS an provide patients with a 2 -week glucose dynamic graph, which can detect blood glucose fluctuations instantly. This provides patients with accurate information and guidance and allows them to adjust measures related to blood glucose levels in a timely manner. In addition, the ISGMS does not require fingertip blood glucose monitoring, and therefore better patient compliance can be achieved $(5,6)$. Previous studies mostly focused on the investigation of glucose monitoring system on the outcome of blood glucose, ignoring its influence on patients' compliance and health behaviors. In this study, we investigated the effects of ISGMs on compliance, health behavior, and body weight in patients with GDM to analyze the clinical promotion value of ISGMs.

We present the following article in accordance with the CONSORT reporting checklist (available at http://dx.doi. org/10.21037/apm-21-439).

\section{Methods}

\section{Patient selection}

A total of 110 GDM patients admitted to our hospital from April 2019 to April 2020 were selected and divided into 2 groups according to the random number table method, with 55 cases in each group. The following inclusion criteria were applied: (I) patients aged 18-42 years old; (II) singleton pregnancies; (III) patients at gestational week 24-28; and (IV) patients who meet the diagnostic criteria for GDM. Patients were excluded from this study if they presented with the following: (I) type 1 diabetes; (II) type 2 diabetes; (III) language communication barriers; (IV) mental illness;
(V) insulin-dependency; and (VI) unwillingness to cooperate during follow-up. This study was approved by the Ethics Committee of Haian People's Hospital \{Ethics approval number: [(2019)KY025]\} and conducted in accordance with the Declaration of Helsinki (as revised in 2013). All subjects provided informed consent.

\section{Interventions}

All patients were followed up by telephone and the WeChat platform. Intervention staff designed home exercise, diet, and other intervention plans for patients based on the results of the blood glucose monitoring.

Patients in the experimental group wore an ISGMS sensor (Abbott Diabetes Care Ltd) with the transient sensor located on the outside of the upper wall of the patient. The ISGMS was used according to the manufacturer's protocols. Briefly, 1 hour after starting the system, a scan was performed and compared to the patient's fingertip blood sugar levels. After wearing the sensor for 2 days, the ISGMS readings were again compared to the fingertip blood glucose values. If there was a difference, the fingertip blood glucose level was considered the accurate measurement. A difference of $1.0 \mathrm{mmol} / \mathrm{L}$ of less was considered within normal limits, and may be due to interstitial fluid and capillary blood glucose self-differentiation. Each day, the patient was required to scan the sensor every 8 hours, and record their medication, daily diet, exercise, and hypoglycemia in a diary. If the sensor glucose monitoring value was below $3.9 \mathrm{mmol} / \mathrm{L}$, it was defined as a low glucose event. Following discharge from hospital, the patients regularly returned for follow-up and interpretation of the detection values, and one sensor can last up to 14 days and does not need to be removed during use. After interpretation and analysis of the monitored values, the patient would be informed of any adjustments to the relevant plan as necessary.

\section{Evaluation indexes}

\section{The incidence of hypoglycemia}

Blood glucose readings less than $3.9 \mathrm{mmol} / \mathrm{L}$ were considered hypoglycemic (7).

\section{The qualified rate of weight gain at the end of pregnancy}

The pre-pregnancy BMI was used to evaluate the qualified weight gain at the end of pregnancy. For patients with 


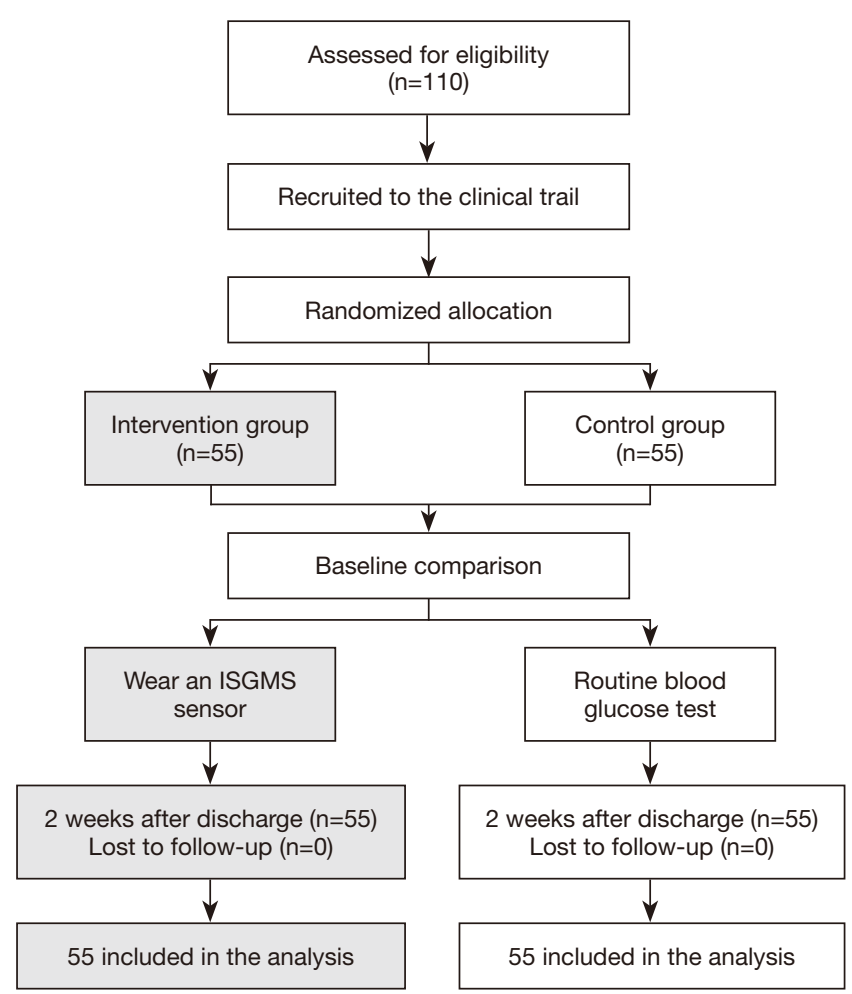

Figure 1 Study profile.

BMI $<18.5 \mathrm{~kg} / \mathrm{m}^{2}$, the recommended weight increase is $12.50-18.00 \mathrm{~kg}$; for patients with $18.5 \leq \mathrm{BMI}<25.0 \mathrm{~kg} / \mathrm{m}^{2}$, the recommended weight increase is $11.50-16.00 \mathrm{~kg}$; for patients with $25.0 \leq \mathrm{BMI}<30 \mathrm{~kg} / \mathrm{m}^{2}$, the recommended weight increase is $7.0-11.50 \mathrm{~kg}$; and for patients with $\mathrm{BMI} \geq 30 \mathrm{~kg} / \mathrm{m}^{2}$, the recommended weight increase is $5.00-9.00 \mathrm{~kg}(8)$.

\section{Compliance with blood glucose monitoring}

Patients who performed blood glucose monitoring 6-7 times daily were considered fully compliant. Patients were considered partially compliant if blood glucose monitoring was performed 3-5 times a day. Patients who only monitored blood glucose levels 1-2 times a day were considered non-compliant. Overall compliance was taken to be full compliance plus partial compliance (9).

\section{Health behavior patterns}

Patient health behaviors such as regular blood glucose monitoring, strict diet control, weight monitoring, appropriate exercise, and regular obstetric checkups were assessed during admission and 2 weeks after the intervention.

\section{Statistical analyses}

Statistical analyses were performed using SPSS22.0 (SPSS Inc., Chicago, IL, USA). Age, pre-pregnancy weight, and pre-pregnancy BMI were expressed as mean \pm standard deviation and compared using two-tailed $t$-tests. The incidence of hypoglycemia, the qualified rate of weight gain at the end of pregnancy, compliance with blood glucose monitoring, and health behavior patterns were expressed as rates and percentages and compared using the $\chi^{2}$ test or rank-sum test. $\mathrm{P}<0.05$ was considered statistically significant.

\section{Results}

\section{General patient information}

This study included 110 patients with GDM. In the control group, the average age was $33.17 \pm 4.08$ years (range 22-41 years), the average pre-pregnancy weight was $50.72 \pm 4.52 \mathrm{~kg}$ (range $45-71 \mathrm{~kg}$ ), and the average pre-pregnancy BMI was $24.59 \pm 2.13 \mathrm{~kg} / \mathrm{m}^{2}$ (range $18.55-31.14 \mathrm{~kg} / \mathrm{m}^{2}$ ). In the ISGMS group, the average age was $32.25 \pm 4.13$ years (range 21-39 years), the average pre-pregnancy weight was $51.18 \pm 4.39 \mathrm{~kg}$ (range $47-73 \mathrm{~kg}$ ), and the average pre-pregnancy BMI was $24.73 \pm 2.09 \mathrm{~kg} / \mathrm{m}^{2}$ (range $18.42-1.26 \mathrm{~kg} / \mathrm{m}^{2}$ ). There were no statistically significant differences between the 2 groups for these parameters ( $\mathrm{P}>0.05$; Figure 1, Table 1).

\section{The incidence of bypoglycemia}

A total of 3 cases $(5.45 \%)$ of hypoglycemia was detected in the ISGMS group, while there were 12 cases (21.82\%) of hypoglycemia in the control group. Therefore, the incidence of hypoglycemia in the ISGMS group was significantly lower than that observed in the control group $\left(\chi^{2}=6.253, \mathrm{P}=0.012 ;\right.$ Table 2$)$.

\section{The qualified rate of weight gain at the end of pregnancy}

In the ISGMS group, 50 cases achieved the qualified weight gain at the end of pregnancy, with a rate of $90.91 \%$. In the control group, 39 cases achieved the qualified weight gain at the end of pregnancy, with a rate of $70.91 \%$. The results demonstrated that the ISGMS group had a higher qualified rate of weight gain at the end of pregnancy compared to the control group $\left(\chi^{2}=7.121, \mathrm{P}=0.008\right.$; Table 3). 
Table 1 General patient information $(\mathrm{n}, \bar{x} \pm \mathrm{S})$

\begin{tabular}{lccc}
\hline Group & Age (years) & Pre-pregnancy weight $(\mathrm{kg})$ & Pre-pregnancy BMl $\left(\mathrm{kg} / \mathrm{m}^{2}\right)$ \\
\hline Control group $(\mathrm{n}=55)$ & $33.17 \pm 4.08$ & $50.72 \pm 4.52$ & $24.59 \pm 2.13$ \\
ISGMS group $(\mathrm{n}=55)$ & $32.25 \pm 4.13$ & $51.18 \pm 4.39$ & $24.73 \pm 2.09$ \\
$t$ value & 1.175 & 0.541 & 0.348 \\
$P$ value & 0.243 & 0.589 & 0.729 \\
\hline
\end{tabular}

$\bar{x}$, mean; S, standard deviation; BMI, body mass index; ISGMS, instantaneous scanning glucose monitoring system.

Table 2 A comparison of the incidence of hypoglycemia between the two groups (n, \%)

\begin{tabular}{|c|c|c|}
\hline Group & Number of cases of hypoglycemia (n) & The incidence of hypoglycemia (\%) \\
\hline ISGMS group $(n=55)$ & 3 & 5.45 \\
\hline$\chi^{2}$ value & & \\
\hline$P$ value & & \\
\hline
\end{tabular}

ISGMS, instantaneous scanning glucose monitoring system.

Table 3 A comparison of the qualified rate of weight gain at the end of pregnancy between the two groups (n, \%)

\begin{tabular}{|c|c|c|c|c|c|c|c|c|c|}
\hline Group & \multicolumn{2}{|c|}{$\mathrm{BMI}<18.5 \mathrm{~kg} / \mathrm{m}^{2}$} & \multicolumn{2}{|c|}{$18.5 \leq \mathrm{BMI}<25.0 \mathrm{~kg} / \mathrm{m}^{2}$} & \multicolumn{2}{|c|}{$25.0 \leq \mathrm{BMI}<30 \mathrm{~kg} / \mathrm{m}^{2}$} & \multicolumn{2}{|c|}{$\mathrm{BMI} \geq 30 \mathrm{~kg} / \mathrm{m}^{2}$} & $\begin{array}{c}\text { The total } \\
\text { qualified rate } \\
\text { of weight } \\
\text { gain }\end{array}$ \\
\hline $\begin{array}{l}\text { Control group } \\
(n=55)\end{array}$ & 0 & 0 & 41 & 28 & 13 & 10 & 1 & 1 & 39 (70.91) \\
\hline$\chi^{2}$ value & \multicolumn{2}{|c|}{-} & \multicolumn{2}{|c|}{4.982} & \multicolumn{2}{|c|}{0.052} & \multicolumn{2}{|c|}{-} & 7.121 \\
\hline$P$ value & \multicolumn{2}{|c|}{ - } & \multicolumn{2}{|c|}{0.026} & \multicolumn{2}{|c|}{0.820} & \multicolumn{2}{|c|}{ - } & 0.008 \\
\hline
\end{tabular}

BMI, body mass index; ISGMS, instantaneous scanning glucose monitoring system.

\section{Compliance with blood glucose monitoring}

In the ISGMS group, 29 participants were completely compliant with blood glucose monitoring, 23 patients were partially compliant, and 3 were non-compliant. The overall compliance rate was $94.55 \%$ in patients who had ISGMS monitoring. In the control group, 20 cases were completely compliant, 21 patients were partially compliant, and 14 participants were non-compliant. The overall compliance rate for the control group $74.55 \%$. These results demonstrated that the ISGMS group had higher blood glucose monitoring compliance compared to the control group $\left(\chi^{2}=8.419, \mathrm{P}=0.004 ;\right.$ Table 4$)$.

\section{Health behavior patterns}

Prior to intervention, there were no statistically significant differences between the 2 cohorts with regards to regular blood glucose monitoring, strict diet control, weight monitoring, appropriate exercise, and regular obstetric checkups $\left(\chi^{2}=0.149,0.039,0.038,0.037\right.$, and 0.227 , respectively; $\mathrm{P}=0.699,0.844,0.846,0.848$, and 0.634 , respectively). However, after 2 weeks of intervention, patients in the ISGMS group showed superior blood glucose monitoring, diet control, weight monitoring, appropriate exercise, and regular obstetric checkups compared to the control cohort $\left(\chi^{2}=116.042,7.066,9.565\right.$, 
Table 4 A comparison of the compliance with blood glucose monitoring between the two groups (n, \%)

\begin{tabular}{lcccc}
\hline Group & Full compliance & Partial compliance & Non-compliance & Compliance \\
\hline Control group $(\mathrm{n}=55)$ & $20(36.36)$ & $21(38.18)$ & $14(25.45)$ & $41(74.55)$ \\
ISGMS group $(\mathrm{n}=55)$ & $29(52.73)$ & $23(41.82)$ & $3(5.45)$ & $52(94.55)$ \\
$\chi^{2}$ value & - & - & - & 8.419 \\
P value & - & - & - & 0.004 \\
\hline
\end{tabular}

ISGMS, instantaneous scanning glucose monitoring system.

Table 5 A comparison of the health behavior patterns between the two groups before and after intervention (n, \%)

\begin{tabular}{|c|c|c|c|c|c|c|}
\hline Time & Group & $\begin{array}{l}\text { Regular blood } \\
\text { glucose monitoring }\end{array}$ & $\begin{array}{l}\text { Strict diet } \\
\text { control }\end{array}$ & $\begin{array}{c}\text { Weight } \\
\text { monitoring }\end{array}$ & $\begin{array}{l}\text { Appropriate } \\
\text { exercise }\end{array}$ & $\begin{array}{c}\text { Regular obstetric } \\
\text { checkups }\end{array}$ \\
\hline \multirow[t]{3}{*}{ On admission } & Control group $(n=55)$ & $33(60.00)$ & $34(61.82)$ & $33(60.00)$ & $31(56.36)$ & $43(78.18)$ \\
\hline & ISGMS group $(n=55)$ & $31(56.36)$ & $35(63.64)$ & $32(58.18)$ & $30(54.55)$ & 45 (81.82) \\
\hline & $\chi^{2}$ value & 0.149 & 0.039 & 0.038 & 0.037 & 0.227 \\
\hline \multirow{3}{*}{$\begin{array}{l}\text { After } 2 \text { weeks of } \\
\text { intervention }\end{array}$} & ISGMS group $(n=55)$ & $55(100.00)$ & $53(96.36)$ & 52 (94.55) & $51(92.73)$ & $55(100.00)$ \\
\hline & $\chi^{2}$ value & 16.042 & 7.066 & 9.565 & 7.698 & 5.492 \\
\hline & $P$ value & 0.000 & 0.008 & 0.002 & 0.006 & 0.019 \\
\hline
\end{tabular}

ISGMS, instantaneous scanning glucose monitoring system.

7.698, and 5.492, respectively; $\mathrm{P}=0.000,0.008,0.002,0.006$, and 0.019 , respectively; Table 5).

\section{Discussion}

In recent years, there has been an increase in the incidence of type 2 diabetes in the younger population, and this has further increased the incidence of GDM (10). The probability of postpartum bleeding in GDM patients is $5 \%$ higher than that in healthy pregnant women, and the probability of puerperal infection is $7 \%$ higher. Traditional blood glucose testing usually evaluates blood glucose levels 2 hours after mealtimes and fasting blood glucose levels. However, it is difficult to dynamically monitor the blood glucose status of patients throughout the day, especially for the detection of reactive hypoglycemia at night $(11,12)$. The ISGMS is a new method of blood glucose monitoring where the patient wears an ISGMS sensor and blood glucose levels can be monitored every 5-10 minutes and recorded through the computer. Thus, the daily fluctuations in the patient's blood glucose levels can be accurately reflected (13). In this study, the ISGMS achieved good results in patients with GDM.

This study demonstrated that the incidence of hypoglycemia in the ISGMS group was significantly lower than that in the control group $(\mathrm{P}<0.05)$, suggesting that using the ISGMS device could effectively reduce the incidence of hypoglycemia in patients with GDM. Since ISGMS can dynamically monitor the patient's blood glucose levels and detect night hypoglycemia as soon as it occurs, medical staff can adjust the relevant doses of hypoglycemic drugs and short-acting insulin in a timely manner to promote the maintenance of blood sugar stabilization, thereby avoiding a significant decrease in blood sugar levels, and ultimately effectively reducing the incidence of hypoglycemia $(14,15)$.

The qualified rate of weight gain at the end of pregnancy in the ISGMS group was also higher than that in the control group $(\mathrm{P}<0.05)$, suggesting that implementation of the ISGMS to monitor blood glucose levels could ensure a reasonable weight gain in patients with GDM. It is likely that using the ISGMS enables the 
patient to see the influence of daily foods on their blood sugar levels, and thus they can be more selective when choosing foods (16). Monitor blood glucose levels in real time also allows the patients to better understand the correlation between daily activities and fluctuations in blood glucose levels. This may improve their subjective initiative and encourage them to increase the amount of exercise to control their weight gain when blood glucose levels are on the rise $(17,18)$.

Furthermore, the ISGMS group achieved higher blood glucose monitoring compliance and better health behaviors compared to the control group after 2 weeks of intervention $(\mathrm{P}<0.05)$. This suggested that the ISGMS could effectively improve the compliance of blood glucose monitoring in patients with GDM and improve patient health behaviors. The ISGMS is painless to wear, and the patient does not need to perform fingertip blood sampling calibration. The sensor worn on the outside of the arm can effectively monitor the patient's blood glucose status in real time, thereby simplifying the monitoring process and improving compliance (19). At the same time, patients can make adjustments to daily exercise and eating routines in response to the real time results of dynamic blood glucose monitoring. This leads to improved control of blood sugar levels and promotes patients to establish healthy behaviors (20).

\section{Conclusions}

The use of the ISGMS in patients with GDM can improve the compliance of blood glucose monitoring, improve health behaviors, reasonably control weight gain, and avoid hypoglycemia.

\section{Acknowledgments}

Funding: This work was supported by grants from the Nantong Health and Family Planning Commission (WKZD2018008), Affiliated Haian Hospital of Nantong University (202010), and the Nantong Science and Technology Board (JCZ20025).

\section{Footnote}

Reporting Checklist: The authors have completed the CONSORT reporting checklist. Available at http://dx.doi. org/10.21037/apm-21-439

Data Sharing Statement: Available at http://dx.doi. org/10.21037/apm-21-439

Conflicts of Interest: All authors have completed the ICMJE uniform disclosure form (available at http://dx.doi. org/10.21037/apm-21-439). The authors have no conflicts of interest to declare.

Ethical Statement: The authors are accountable for all aspects of the work in ensuring that questions related to the accuracy or integrity of any part of the work are appropriately investigated and resolved. This study was approved by the Ethics Committee of Haian People's Hospital \{Ethics approval number: [(2019)KY025]\} and conducted in accordance with the Declaration of Helsinki (as revised in 2013). All subjects provided informed consent.

Open Access Statement: This is an Open Access article distributed in accordance with the Creative Commons Attribution-NonCommercial-NoDerivs 4.0 International License (CC BY-NC-ND 4.0), which permits the noncommercial replication and distribution of the article with the strict proviso that no changes or edits are made and the original work is properly cited (including links to both the formal publication through the relevant DOI and the license). See: https://creativecommons.org/licenses/by-nc-nd/4.0/.

\section{References}

1. Nigam A, Varun N, Sharma S, et al. Glycaemic profile in the second and third trimesters of normal pregnancy compared to non-pregnant adult females. Obstet Med 2020;13:30-6.

2. Shaw M, Lutz T, Gordon A. Does low body fat percentage in neonates greater than the 5 th percentile birthweight increase the risk of hypoglycaemia and neonatal morbidity. J Paediatr Child Health 2019;55:1424-8.

3. Nally LM, Bondy N, Doiev J, et al. A Feasibility Study to Detect Neonatal Hypoglycemia in Infants of Diabetic Mothers Using Real-Time Continuous Glucose Monitoring. Diabetes Technol Ther 2019;21:170-6.

4. Mao P, Jiang S, Guo J, et al. Do obesity and low levels of physical activity increase the risk for developing type 2 diabetes mellitus among women with prior gestational diabetes in rural China. Res Nurs Health 2020;43:387-95.

5. Bülbül A, Bahar S, Uslu S, et al. Risk Factor Assessment and the Incidence of Neonatal Hypoglycemia in the Postnatal Period. Sisli Etfal Hastan Tip Bul 2019;53:389-94.

6. Youngwanichsetha S, Phumdoung S. Lived experience of 
blood glucose self-monitoring among pregnant women with gestational diabetes mellitus: a phenomenological research. J Clin Nurs 2017;26:2915-21.

7. Singh N, Madhu M, Vanamail P, et al. Efficacy of metformin in improving glycaemic control \& perinatal outcome in gestational diabetes mellitus: A nonrandomized study. Indian J Med Res 2017;145:623-8.

8. Feng $\mathrm{L}, \mathrm{Xu} \mathrm{Q}, \mathrm{Hu} \mathrm{Z}$, et al. Lactation and progression to type 2 diabetes in patients with gestational diabetes mellitus: A systematic review and meta-analysis of cohort studies. J Diabetes Investig 2018;9:1360-9.

9. Jia L, Cao M, Chen H, et al. Butyrate Ameliorates Antibiotic-Driven Type 1 Diabetes in the Female Offspring of Nonobese Diabetic Mice. J Agric Food Chem 2020;68:3112-20.

10. Saw HP, Yao NW, Chiu CD, et al. The value of real-time continuous glucose monitoring in premature infants of diabetic mothers. PLoS One 2017;12:e0186486.

11. Lemelin A, Paré G, Bernard S, et al. Demonstrated CostEffectiveness of a Telehomecare Program for Gestational Diabetes Mellitus Management. Diabetes Technol Ther 2020;22:195-202.

12. Uma R, Bhavadharini B, Ranjani H, et al. Pregnancy outcome of gestational diabetes mellitus using a structured model of care: WINGS project (WINGS-10). J Obstet Gynaecol Res 2017;43:468-75.

13. Mensah GP, Ten Ham-Baloyi W, van Rooyen DRM, et al. Guidelines for the nursing management of gestational diabetes mellitus: An integrative literature review. Nurs

Cite this article as: Zhang X, Jiang D, Wang X. The effects of the instantaneous scanning glucose monitoring system on hypoglycemia, weight gain, and health behaviors in patients with gestational diabetes: a randomised trial. Ann Palliat Med 2021;10(5):5714-5720. doi: 10.21037/apm-21-439
Open 2019;7:78-90.

14. Deepaklal MC, Joseph K, Kurian R, et al. Efficacy of insulin lispro in improving glycemic control in gestational diabetes. Indian J Endocrinol Metab 2014;18:491-5.

15. Harrison AL, Taylor NF, Frawley HC, et al. A consumer co-created infographic improves short-term knowledge about physical activity and self-efficacy to exercise in women with gestational diabetes mellitus: a randomised trial. J Physiother 2020;66:243-8.

16. Lv S, Yu S, Chi R, et al. Effects of nutritional nursing intervention based on glycemic load for patient with gestational diabetes mellitus. Ginekol Pol 2019;90:46-9.

17. Egan AM, Bogdanet D, Griffin TP, et al. A core outcome set for studies of gestational diabetes mellitus prevention and treatment. Diabetologia 2020;63:1120-7.

18. Utz B, Assarag B, Lekhal T, et al. Implementation of a new program of gestational diabetes screening and management in Morocco: a qualitative exploration of health workers' perceptions. BMC Pregnancy Childbirth 2020;20:315.

19. Park S, Lee JL, In Sun J, et al. Knowledge and health beliefs about gestational diabetes and healthy pregnancy's breastfeeding intention. J Clin Nurs 2018;27:4058-65.

20. Terry MA, Stotz SA, Charron-Prochownik D, et al. Recommendations from an expert panel of health professionals regarding a gestational diabetes risk reduction intervention for American Indian/Alaska Native Teens. Pediatr Diabetes 2020;21:415-21.

(English Language Editor: J. Teoh) 